\title{
ФУКСИТ В МЕТАПЕСЧАНИКАХ СТОЙЛЕНСКОЙ СВИТЫ КУРСКОЙ СЕРИИ КМА (ОСОБЕННОСТИ МИНЕРАЛОГИИ, УСЛОВИЯ ОБРАЗОВАНИЯ)
}

\author{
С. М. Пилюгин, А. В. Никитин, Т. Н. Полякова \\ Воронежский государственный университет \\ Поступила в редакцию 30 апреля 2019 г.
}

\begin{abstract}
Аннотация: в работе приводится детальная минералогическая характеристика фукситовых метапесчаников стойленской свиты курской серии КМА. Охарактеризованы их породообразующие и акиессорные минераль. Установлено развитие в метаосадочных породах фуксита $\left(\mathrm{K}(\mathrm{Al}, \mathrm{Cr})_{3} \mathrm{Si}_{3} \mathrm{O}_{10}(\mathrm{OH})_{2}\right)$ за счет дегидратации гидрослюд и разложения детритовых кристаллов феррохромита в условиях эпидот-амфиболитовой фации метаморфизма.

Ключевые слова: Курская магнитная аномалия, протерозой, стойленская свита, фуксит, феррохромит.

\section{FUCHSITE IN META-SANDSTONE OF THE STOILENSKAYA SUITE OF THE KURSK SERIES KURSK MAGNETIC ANOMALY (FEATURES OF MINERALOGY, CONDITIONS OF FORMATION)}

Abstract: the work presents a detailed mineralogical characteristic of the Fuchsite meta-sandstone of the Stoilenskaya suite of the Kursk series KMA. The rock-forming and accessory minerals are characterized. The development of fuchsite $\left(\mathrm{K}(\mathrm{Al}, \mathrm{Cr})_{3} \mathrm{Si}_{3} \mathrm{O}_{10}(\mathrm{OH})_{2}\right)$ in metasedimentary rocks has been established due to dehydration of hydro-mica and decomposition of ferro-chromite detrital crystals under conditions of epidote-amphibolite facies of the metamorphism.
\end{abstract}

Key words: Kursk magnetic anomaly, Proterozoic, Stoilenskaya suite, Fuchsite, Ferro-chromite.

\section{Введение}

Стойленская свита курской серии палеопротерозоя Воронежского кристаллического массива (ВКМ) занимает особое место в метаморфических образованиях Курской магнитной аномалии (КМА). Ее накопление маркирует начало развития морского бассейна, в котором на терригенных породах отлагались хемогенные железисто-кремнистые осадки, преобразованные при метаморфизме в железистые кварциты коробковской свиты. Ими сложены месторождения железа мирового класса (Коробковское, Лебединское, Стойленское и Михайловское).

Стойленская свита представлена в разрезах сланцами и кварцито-песчаниками, метаморфизованными в условиях эпидот-амфиболитовой фации метаморфизма. Породы стойленской свиты вскрыты и прослежены в коренном залегании в восточном и юговосточном ответвлении шахтных стволов Коробковского месторождения (рис. 1).

В нижней части стойленской свиты фиксируются фукситовые метапесчаники, в качестве источников обломочного материала для которых традиционно рассматриваются метаморфизованные протолиты михайловской серии неоархея [1]. Среди возможных источников называются различные по составу образования (от гипербазитов до гранодиоритов) [2], однако, эти данные носят предположительный характер и нуждаются в дополнительных исследованиях, в том числе на детальном вещественном уровне. Этому решению посвящена настоящая статья.

\section{Петрография и минералогия}

Фукситовые метапесчаники были отобраны в юговосточном ответвлении шахтного ствола №4 Коробковского месторождения (горизонт -71м) (рис. 1). Они представлены породой травянисто-зеленого, реже зеленовато-бирюзового цвета с полосчатой текстурой. Структура породы гранобластовая, лепидогранобластовая в некоторых случаях порфиробластовая за счет присутствия крупных (0,5 см) выделений голубовато-серого кварца. Основными породообразующими минералами фукситовых метапесчаников является кварц и зеленоватая хромсодержащая разновидность мусковита - фуксит. Фуксит в проходящем 


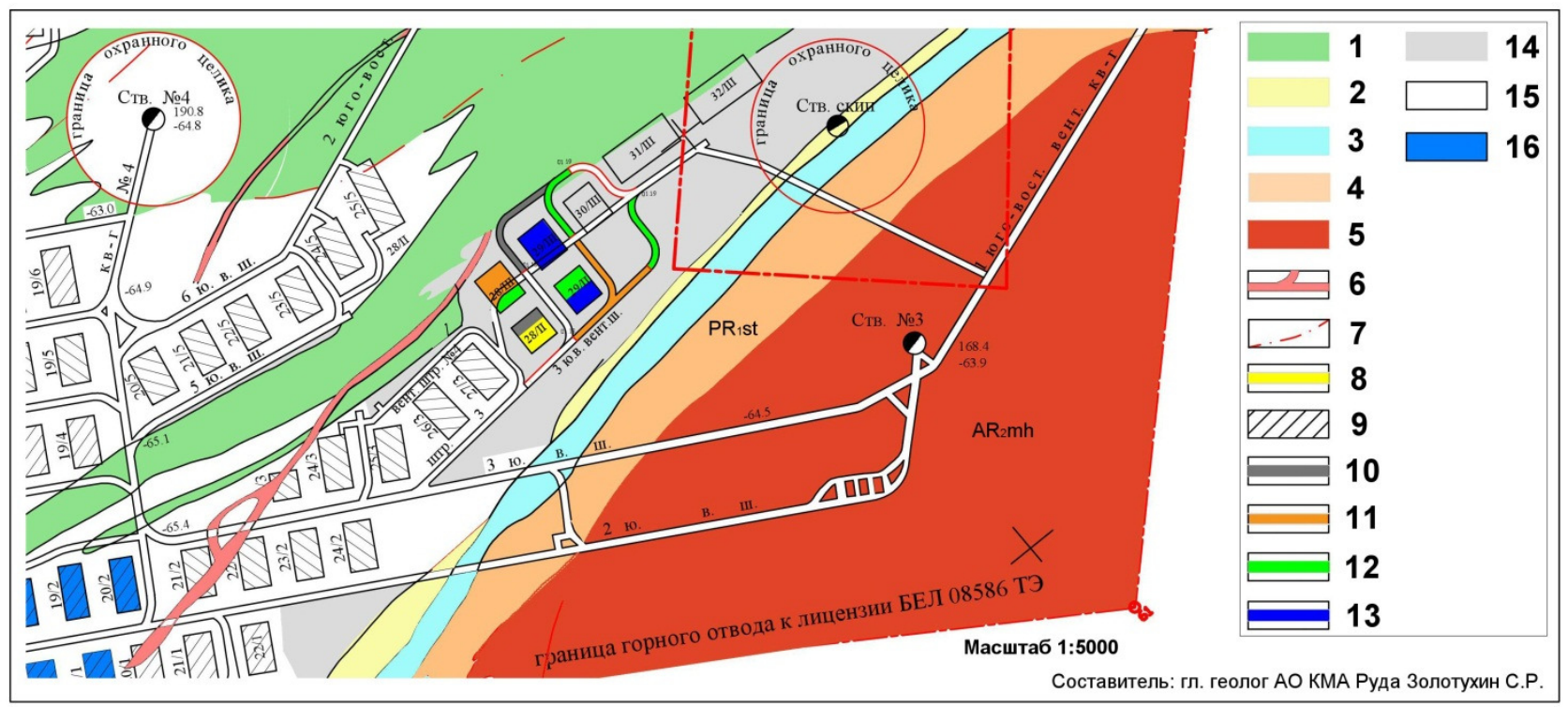

Puc. 1. Схема геологического строения юго-восточного ответвления шахтного ствола Коробковского месторождения (горизонт -71 м): 1 - гранат-амфиболовые сланцы; 2 - слабо-рудные кварциты; 3 - кварц-серицитовые сланцы; 4 - кварцитопесчаники; 5 - гранито-гнейсы; 6 - жильные образования; 7 - тектонические нарушения; 8 - действующие камеры; 9 - отработанные камеры; 10 - 1 квартал 2018 г.; 11 - 2 квартал 2018 г.; 12 - 3 квартал 2018 г.; 13 - 4 квартал 2018 г.; 14 - балансовые запасы железистых кварцитов; 15 - временно неактивные запасы железистых кварцитов; 16 - заложенное выработанное пространство.

свете темно-зеленый, мелкочешуйчатый, в скрещенных николях плеохроирует в радужных тонах. Для кварцевых агрегатов характерна слабо вытянутая, реже неправильная, для фуксита - почти всегда мелкочешуйчатая ориентированная по направлению полосчатости форма. Размеры кристаллов варьируют в широких пределах - от нескольких микрон до 2-3 мм. Микроскопически кристаллы фуксита «собраны» в породе в отдельные сегменты (кластеры), окруженные со всех сторон кварцем (рис. 2 а).

По данным энергодисперсионного микроанализа фуксит содержит примеси хрома (3,4-3,8 мас.\% $\mathrm{Cr}_{2} \mathrm{O}_{3}$ ), а также незначительные примеси железа, магния, титана и натрия (табл. 1). Изоморфное замещение трехвалентного алюминия на хром в катионном комплексе мусковита $\left(\mathrm{K}(\mathrm{Al}, \mathrm{Cr})_{3} \mathrm{Si}_{3} \mathrm{O}_{10}(\mathrm{OH})_{2}\right)$ ведет к образованию фуксита.

При детальном изучении образцов на растровом электронном микроскопе Jeol 6380 LV с энергодисперсионной системой количественного анализа Inca250 (ВГУ) было установлено, что фукситовые кластеры в центральных частях содержат небольшие (150200 мкм) корродированные и фрагментированные кристаллы хромита (рис. 2 а). По химическому составу это практически чистые феррохромиты [3], с небольшими примесями цинка (1,3 мас.\% $\mathrm{ZnO})$, магния и марганца (табл. 2).
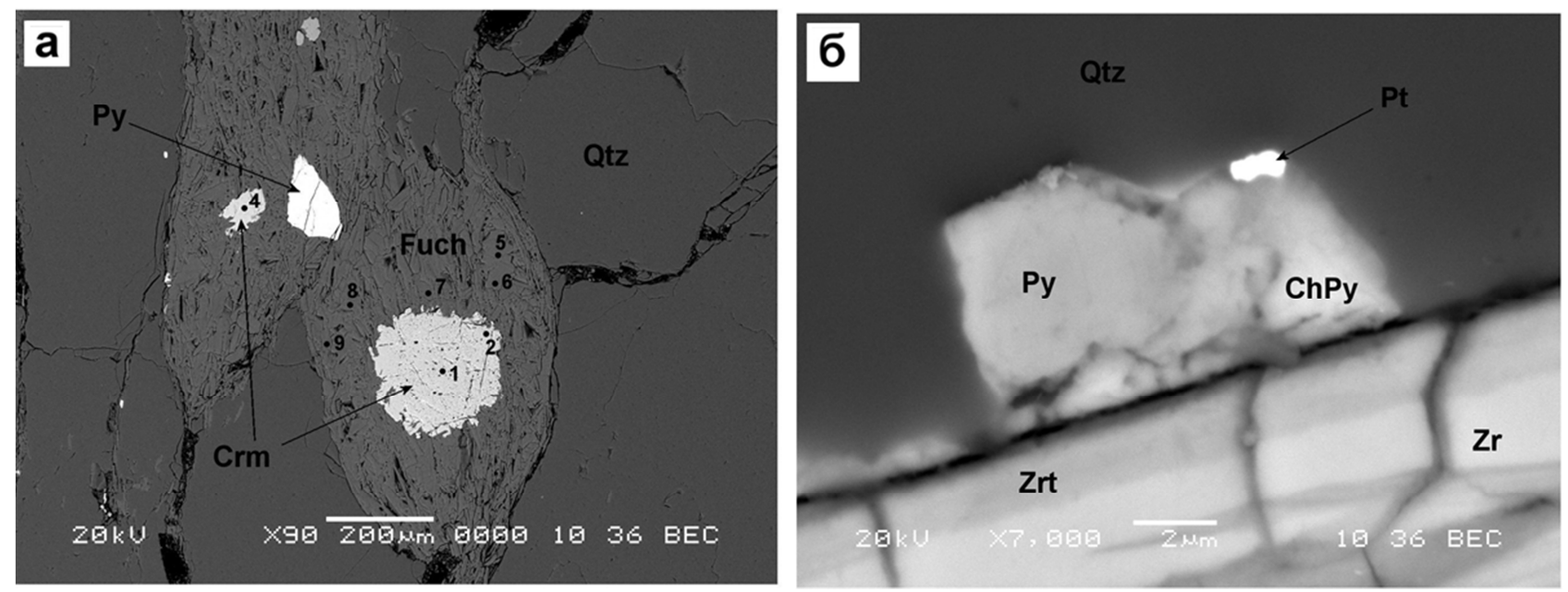

$P u c$. 2. Микрофотографии минеральных ассоциаций фукситовых метапесчаников: Fuch - фуксит; Crm - хромит; Py- пирит; $Q t z$ - кварц; $C h P y$ - халькопирит; $Z r$ - циркон; $Z r t$ - циртолит; $P t$ - самородная платина. 
Фуксит в метапесчаниках стойленской свиты Курской серии КМА ...

Таблица 1

Таблица 2

Химические составы фуксита, полученные по данным точечного рентгеноспектрального микроанализа

\begin{tabular}{|c|c|c|c|c|c|}
\hline № анализа & 5 & 6 & 7 & 8 & 9 \\
\hline $\mathrm{SiO}_{2}$ & 46,73 & 45,29 & 46,22 & 45,14 & 46,52 \\
\hline $\mathrm{TiO}_{2}$ & 0,94 & 0,64 & 0,51 & 0,79 & 0,82 \\
\hline $\mathrm{Al}_{2} \mathrm{O}_{3}$ & 31,56 & 31,58 & 30,64 & 30,84 & 31,01 \\
\hline $\mathrm{Cr}_{2} \mathrm{O}_{3}$ & 3,8 & 3,61 & 3,46 & 3,46 & 3,49 \\
\hline $\mathrm{FeO}$ & 0,73 & 0,71 & 0,57 & 0,52 & 0,6 \\
\hline $\mathrm{MgO}$ & 1,39 & 1,32 & 1,28 & 1,28 & 1,11 \\
\hline $\mathrm{Na}_{2} \mathrm{O}$ & 0,71 & 0,64 & 0,38 & 0,77 & 0,75 \\
\hline $\mathrm{K}_{2} 0$ & 10,32 & 10,19 & 10,25 & 9,82 & 10,31 \\
\hline $\mathrm{CyMмa} \mathrm{96,18}$ & 93,98 & 93,31 & 92,62 & 94,61 \\
\hline $\mathrm{Si}$ & 3,12 & 3,09 & 3,18 & 3,12 & 3,16 \\
\hline $\mathrm{Ti}$ & 0,05 & 0,03 & 0,03 & 0,04 & 0,04 \\
\hline $\mathrm{Al}$ & 2,48 & 2,54 & 2,49 & 2,51 & 2,48 \\
\hline $\mathrm{Cr}$ & 0,20 & 0,19 & 0,19 & 0,19 & 0,19 \\
\hline $\mathrm{Fe} " '$ & 0,00 & 0,00 & 0,00 & 0,00 & 0,00 \\
\hline $\mathrm{Fe}$ & 0,04 & 0,04 & 0,03 & 0,03 & 0,03 \\
\hline $\mathrm{Mg}$ & 0,14 & 0,13 & 0,13 & 0,13 & 0,11 \\
\hline $\mathrm{Na}$ & 0,09 & 0,08 & 0,05 & 0,10 & 0,10 \\
\hline $\mathrm{K}$ & 0,88 & 0,89 & 0,90 & 0,87 & 0,89 \\
\hline
\end{tabular}

Акцессорная минерализация изученных пород представлена достаточно широко. Были обнаружены: сульфиды (пирит, халькопирит, пирротин, пентландит, молибденит), фосфаты (монацит, ксенотим), окислы и силикаты (рутил, касситерит, циркон, торит), самородные минералы (платина), карбонаты (сидерит).

Новообразованными (метаморфическими) акцессорными минералами в фукситовых метапесчаниках являются все прожилковые выделения сульфидов, а также фосфаты. К примеру, было установлено, что при переходе от зеленосланцевой к эпидот-амфиболитовой фации метаморфизма детритовых кристаллов монацита в породе не остается [4]. К детритовым минералам можно отнести хорошо окатанные мелкие (1-5 мкм) кристаллы платины, касситерита, а также циркона.

Большинство изученных кристаллов циркона характеризуется зональной структурой, подчеркнутой процессами циртолитизации (гидроокисным замещением $\mathrm{H}_{2} \mathrm{O}=12-15$ мас.\%) (рис. 2 б). В фукситовых метаконгломератах нами был обнаружен кристалл самородной платины с примесью родия $(\mathrm{Rh}=0,8$ вес.\%), находящейся в ассоциации с пиритом и халькопиритом (рис. 2 б).

\section{Интерпретация полученных результатов}

Исходя из проведенных нами петрографических наблюдений и анализа особенностей химического состава породообразующих минералов, можно сформулировать следующую последовательность образования фукситовых метапесчаников: на стадии диакатагенеза была сформирована цементирующая квар-
Химические составы хромита, полученные по данным точечного рентгеноспектрального микроанализа

\begin{tabular}{|c|c|c|c|}
\hline № анализа & 1 & 2 & 4 \\
\hline $\mathrm{TiO}_{2}$ & 0,00 & 0,37 & 0,29 \\
\hline $\mathrm{Al}_{2} \mathrm{O}_{3}$ & 14,68 & 15,73 & 15,74 \\
\hline $\mathrm{Cr}_{2} \mathrm{O}_{3}$ & 51,10 & 49,93 & 50,09 \\
\hline $\mathrm{FeO}$ & 33,20 & 33,55 & 32,32 \\
\hline $\mathrm{MnO}$ & 0,80 & 0,78 & 0,60 \\
\hline $\mathrm{MgO}$ & 0,44 & 0,32 & 0,51 \\
\hline $\mathrm{ZnO}$ & 1,32 & 1,48 & 1,45 \\
\hline $\mathrm{Cyммa}$ & 101,54 & 102,16 & 101,00 \\
\hline $\mathrm{Ti}$ & 0,00 & 0,01 & 0,01 \\
\hline $\mathrm{Al}$ & 0,59 & 0,63 & 0,63 \\
\hline $\mathrm{Cr}$ & 1,38 & 1,34 & 1,35 \\
\hline $\mathrm{Fe} " '$ & 0,03 & 0,02 & 0,00 \\
\hline $\mathrm{Fe}$ & 0,92 & 0,93 & 0,92 \\
\hline $\mathrm{Mn}$ & 0,02 & 0,02 & 0,02 \\
\hline $\mathrm{Mg}$ & 0,02 & 0,02 & 0,03 \\
\hline $\mathrm{Zn}$ & 0,04 & 0,04 & 0,04 \\
\hline
\end{tabular}

цевые зерна (и детритовые акцессории) минеральная масса, представленная преимущественно гидрослюдой. Процесс фазового перехода (перекристаллизации) глинистых минералов (каолинита, либо монтмориллонита) в минералы группы гидрослюд (иллита, серицитового мусковита) подробно описан в ряде работ $[5,6]$ (в том числе экспериментальных [7]). Стоит отметить, что основным параметром перехода является адсорбция глинистыми минералами калия из морской воды [8]:

$$
\underset{\text { Каолинит }}{3 \mathrm{Al}_{4} \mathrm{Si}_{4} \mathrm{O}_{10}(\mathrm{OH})_{8}}+4 \mathrm{~K}^{+}=4 \mathrm{KAl}_{3} \mathrm{Si}_{3} \mathrm{O}_{10}(\mathrm{OH})_{2}+6 \mathrm{H}_{2} \mathrm{O}+4 \mathrm{H}^{+}
$$

Далее, при повышении температуры и давления в ходе регионального метаморфизма, происходила дегидратация цементирующего материала (иллита, серицита) с образованием активного (возможно щелочного) флюида, корродирующего кристаллы феррохромита (рис. 2 а). К примеру, реакция разложения феррохромита в лабораторных условиях за счет гидроксида калия в бескислородной среде хорошо известна:

$$
\mathrm{Fe}\left(\mathrm{CrO}_{2}\right)_{2}+6 \mathrm{KOH}+4 \mathrm{H}_{2} \mathrm{O} \stackrel{\mathrm{N}_{2}}{\rightarrow} 2 \mathrm{~K}_{3}\left[\mathrm{Cr}(\mathrm{OH})_{6}\right]+\mathrm{Fe}(\mathrm{OH})_{2} \downarrow
$$

При этом, образуется комплексное соединение гексагидроксохромат калия $\left(\mathrm{K}_{3}\left[\mathrm{Cr}(\mathrm{OH})_{6}\right]\right)$ неустойчивое при повышении температуры.

Таким образом, изовалентное замещение алюминия на хром в структуре серицита, вероятно, связано с инфильтрационной активностью флюида при проградном метаморфизме. Гомогенные составы как 
фуксита, так и феррохромита подтверждают наше предположение - в ультрамафитовых ксенолитах вулканогенно-осадочного комплекса месторождения Альмаден (Испания) [9] были описаны процессы гидротермального замещения хромовой шпинели фукситом и хромсодержащим хлоритом с большими вариациями химических составов всех реагирующих минералов.

\section{Заключение}

Проведенное исследование позволило сформулировать следующие основные выводы:

1. Фуксит образовался за счет метаморфической перекристаллизации тонкокристаллического серицита с изовалентным замещением в катионном комплексе алюминия хромом.

2. Источником хрома для образования фуксита являлись продукты растворения корродированных кристаллов феррохромита.

3. Акцессорная минерализация фукситовых метапесчаников (самородная платина, минералы никеля, касситерит, циркон, торит) косвенно подтверждает существование архейского бимодального магматизма ВКМ в условиях внутриконтинентального рифтогенеза.

Авторы благодарят к. г.-м. н. И. П. Лебедева за весьма полезные и продуктивные замечания и предложения, сделанные при подготовке рукописи стаmьи.

ФГБОУ ВО «Воронежский государственный университет»

Пилюгин Сергей Михайлович, кандидат геолого-

минералогических наук, доцент кафедры полезных ископаемых и недропользования,

E-mail: geoscience@yandex.ru

Тел.: +7 (473) 2208626

Никитин Александр Васильевич, кандидат геологоминералогических наук, дочент кафедры общей геологии и геодинамики

E-mail: nikav_1960@mail.ru

Тел.: +7 (473)2208588

Полякова Татьяна Николаевна, кандидат геологоминералогических наук, дочент кафедры полезных ископаемых и недропользования

E-mail:imgre2010@yandex.ru

Тел.: +7 (473)2208626

\section{ЛИТЕРАТУРА}

1. Полищук, В. Д. Метаморфические комплексы фундамента бассейна Курской магнитной аномалии (КМА). / В. Д. Полищук, В. И. Полищук // В сб. Метаморфические комплексы фундамента Русской плиты (ред. В. Б. Дагелайский и Л. П. Бондаренко). - 1978. - С. 131-156.

2. Чернышов, Н. М. О принадлежности золото-платинометалльного оруденения в железистых кварцитах и сланцах КМА к единой рудообразующей системе / Н. М. Чернышов // Вестник Воронеж. гос. ун-та. Сер. Геология. - 2014. № 2. - C.88-96.

3. Дир, У. А. Породообразующие минералы / У. А. Дир, Р. А. Хауи, Дж. Зусман. - Издательство «Мир». Том № 5. 1966. $-94 \mathrm{c}$.

4. Rasmussen, B. Monazite begets monazite: eviidence for dissolution of detrital monazite and reprecipitation of syntectonic monazite during low_grade regional metamorphism / B. Rasmussen, J. R. Muhling // Contrib. Mineral. Petrol. - 2007. - V. 154. - P. 675-689.

5. Dietz, R. S. Clay minerals in recent marine sediments / R. S. Dietz // Am. Mineral. - 1942. - V. 27. - P. 219.

6. Yoder, H. S. Synthetic and natural muscovites / H. S. Yoder, H. P. Eugster // Geochim. et Cosmochim. Acta. - 1955. - V. 8. - P. 225.

7. Caillere, S. Tranformation experimentale d'une montmorillonite en une phyllite a 10 A type illite / S. Caillere, S. Henin // Comp. Rend. Acad. Sci Paris. - 1948. - V. 226. - P. 680.

8. Grim, R. E. The mica in argillaceous sediments / R. E. Grim, R. H. Bray, W. F. Bradley // Am. Mineral. - 1937. - V. 22. - P. 813.

9. Morata, D. Fuchsite and other Cr-rich phyllosilicates in ultramafic enclaves from Almadén mercury mining district, Spain / D. Morata, P. Higueras, S. Dominguez-Bella // Clay minerals. - 2001. - V. 36. - P. 345-354.

\section{Voronezh State University}

Pilyugin S. M., Candidate of Geological and Mineralogical Sciences, associate professor of the Mineral Resource Department

E-mail: geoscience@yandex.ru

Tel.: +7 (473) 2208626

Nikitin A. V., Candidate of Geological and Mineralogical Sciences, Associate Proffessor of the General Geology and Geodynamics Department

E-mail:nikav_1960@mail.ru

Tel.: +7 (473)2208588

Polyakova T. N., Candidate of Geological and Mineralogical Sciences, associate professor of the Mineral Resource Department

E-mail: imgre2010@yandex.ru Tel.: +7 (473)2208626 